\title{
Optimizing Emitters' Density and Water Supplies in Trickle Irrigation Systems
}

\author{
Hammami Moncef ${ }^{1, \text { * }}$, Zayani Khemaies ${ }^{2}$ \\ ${ }^{1}$ Hydraulic Department, Higher School of Engineers Medjez El Bab, University of Jendouba, Jendouba, Tunisia \\ ${ }^{2}$ Department of Rural Engineering, National Agronomic Institute of Tunis, University of Carthage, Tunis, Tunisia
}

Email address:

hammami.moncef@ymail.com (H. Moncef), zayani.khemaies@gmail.com (Z. Khemaies)

${ }^{*}$ Corresponding author

To cite this article:

Hammami Moncef, Zayani Khemaies. Optimizing Emitters' Density and Water Supplies in Trickle Irrigation Systems. American Journal of Water Science and Engineering. Vol. 5, No. 1, 2019, pp. 16-21. doi: 10.11648/j.ajwse.20190501.13

Received: December 9, 2018; Accepted: January 30, 2019; Published: February 28, 2019

\begin{abstract}
The usual approaches for designing trickle irrigation systems are based upon empirical estimation of the emitters' density and the moistened soil volume. The objective of this paper is to implement a quasi-analytical approach that allows the inference of these two parameters. The emitters' density is determined so that the rooted soil volume would be moistened even at the peak period. The proposed approach enables to adjust the irrigation time in order to replenish the rooted soil volume up to a threshold for an optimal plant growth. The required inputs are: the water retention curve, the hydraulic conductivity at the wetting front, the radius of the moistened spot at the soil surface, and the rooted soil depth. The method is assessed with respect to study cases for sandy and silty soils. The used emitters' discharge were $2 \mathrm{l} / \mathrm{h}$ and $4 \mathrm{l} / \mathrm{h}$. The present approach has the advantage of preserving the mass conservation as well as the dynamic aspect of irrigation management. For design purpose, the irrigation time is set equal to the time required to attain a quasi-state flow conditions within the rooted zone. Nevertheless, irrigation time should vary so that design errors are adjusted for irrigation scheduling needs.
\end{abstract}

Keywords: Trickle Irrigation, Wetted Soil Volume, Emitters' Density, Irrigation Management

\section{Introduction}

Trickle irrigation is characterized by small and frequent water supplies. Notwithstanding the partial moistening of the rooted zone, the crop growth is optimum. The most important advantages of the trickle irrigation system are:

1) the lessening of the effectively wetted area on the soil surface. Subsequently, water evaporation and weeds proliferation are reduced. Thus, concomitant agricultural activities are possible [1-3].

2) the reduction of the moistened soil volume. Therefore, less deep-water percolation, less fertilizers' leaching and less water table contamination are expected [3].

Thus, wise trickle irrigation management requires the computation of the fraction of the effectively wetted soil volume P. It is worth emphasizing that the inference of $\mathrm{P}$ is challenging insofar as it depends on more or less hardly predictable factors such as roots' length density, distribution uniformity, initial water content, physical soil properties, etc.
Several methods are available in literature for predicting P. They could be classified into three approaches:

1) empirical approaches: many empirical expressions were derived for predicting moistened bulb [4-6]. Keller and Karmelli [7] developed an empirical method to infer the emitters' spacing from the soil texture, the emitters' discharges for a gross water depth of $40 \mathrm{~mm}$. Recently, Ahmed et al. [8] developed an enhanced model to estimate the radius of the wet spot at the soil surface and the wetted depth as function of application time, emitter discharge, soil bulk density, initial soil moisture content, saturated hydraulic conductivity and the particle soil size distribution. This model has the advantage of being valid for homogeneous and heterogeneous soil profiles. Nevertheless, 16 empirical coefficients should be fitted for each study case. Because of their simplicity, the empirical methods remain enticing.

2) numerical approaches: several models were elaborated to simulate soil water distribution beneath point and 
linear sources (either buried or not) [9-13]. Despite their accuracy and usefulness for complex situations, numerical approaches are somewhat cumbersome and requires the previous knowledge of soil water properties. Besides, the extension of the ponding radius on the soil surface with respect to the elapsed time is almost inaccurately estimated [10].

3) analytical approaches: many analytical solutions were inferred from solving Richard's equation under steady state and transient conditions for surface and buried point sources. The computational easiness, the general insight and the explicit relationships between inputs and outputs make analytical solutions useful tools for trickle network design and irrigation management. Nevertheless, these approaches are only valid under drastic assumptions (steady state conditions, linear soils, homogeneous initial soil profile, etc.). Revol et al. [14] recorded large discrepancies between Wooding [15], Raats [16] and Philip's [17] solutions for predicting the radius of the ponded spot $R_{s}(t)$ beneath a surface point source. In bare soils, Sen et al., [18] and Coelho and Or [19] reported that the accuracy of Warrick's solution [20] hinges on the selection of the constant $\mathrm{k}(\mathrm{k}=\mathrm{dK} / \mathrm{d} \theta)$. Coelho and Or [19] have shown that the superposition of plant uptake with Warrick's [20] solution seems to provide reliable results. Communar and Friedman [12] provided analytical solutions to the unsteady three-dimensional infiltration from surface or subsurface point sources. These solutions are based on the following assumptions: (1) the surface evaporation is linearly dependent on the matric flux potential and (2) the hydraulic conductivity is an exponential function of the pressure head and soil depth. Hammami and Zayani [3] developed an analytical method to estimate the volume of the wetted bulb underneath a surface emitter. This method is based on the following hypothesis: (1) the wetted soil depth is inferred from the surface wetted radius according to the method of Hammami et al. [21], (2) the water flow is of piston-type and (3) the wetted bulb is of semi-elliptical shape which diagonals are confined with the soil surface and the symmetry axis, respectively.

This paper is devoted to expanding the approach of Hammami and Zayani [3] to the computation of emitters' density and water supplies. The implementation of the proposed approach is assessed with respect to study cases.

\section{Theoretical Basis}

From continuity standpoint, horizontal and vertical infiltration's equations, Hammami et al. [21], proposed:

$$
Z_{f}(\mathrm{t})=R_{f}(\mathrm{t})+\frac{K_{f} . \mathrm{t}}{2\left(\theta_{f}-\theta_{i}\right)}
$$

where $Z_{f}, R_{f}$ and $t$ refer to the depth of the wetting front [L] along the symmetric axis $\mathrm{OZ}$, the radius of wetted spot [L] at the soil surface and the elapsed time $t[T]$, respectively. The parameters $\theta_{\mathrm{f}}, \theta_{\mathrm{i}}$ and $\mathrm{K}_{\mathrm{f}}$ refer to the water content $\left[\mathrm{L}^{3} \mathrm{~L}^{-3}\right]$ at the wetting front, initial water content $\left[\mathrm{L}^{3} \mathrm{~L}^{-3}\right]$ and soil hydraulic conductivity $\left[\mathrm{LT}^{-1}\right]$ at the pressure head $\mathrm{h}_{\mathrm{f}}[\mathrm{L}]$ prevailing at the front position, respectively.

It is worth emphasizing that equation (1) satisfies the boundary conditions of an axisymmetric water infiltration from a surface point source. Equation (1) has the advantage of providing the depth of the moistened front (invisible) from the radius of the wet spot on the soil surface. Subsequently, deep percolation, nutrients leaching and water table contamination would be controlled. Nevertheless, equation (1) remains valid for the infiltration process even though the redistribution is dominant during the irrigation cycle. In what follows, the volume of the wetted bulb $\mathrm{V}_{\mathrm{b}}(\mathrm{t})\left[\mathrm{L}^{3}\right]$ is assumed to be of an ellipsoidal shape which horizontal and vertical diagonals are respectively confined with soil surface and symmetry axis. According to Hammami and Zayani [3], $\mathrm{V}_{\mathrm{b}}(\mathrm{t})$ is given by:

$$
V_{b}(\mathrm{t})=\frac{2 \pi}{3} R_{f}(\mathrm{t})^{2}\left(2 R_{f}(\mathrm{t})+\frac{K_{f} \cdot \mathrm{t}}{\left(\theta_{f}-\theta_{i}\right)}\right)
$$

Equation (2) shows that $\mathrm{V}_{\mathrm{b}}(\mathrm{t})$ depends on soil conditions $\left(\mathrm{K}_{\mathrm{f}}, \theta_{\mathrm{f}}\right.$ and $\left.\theta_{\mathrm{i}}\right)$, emitters'discharge and irrigation management. For the same wetted bulb volume, as the term $\mathrm{K}_{\mathrm{f} . \mathrm{t}} \mathrm{t}\left(\theta_{\mathrm{f}}-\theta_{\mathrm{i}}\right)$ increases, the term $2 \mathrm{R}_{\mathrm{f}}(\mathrm{t})$ decreases. Therefore, the wetted bulb is vertically elongated in sandy soils or when small emitters' discharges are used. Conversely, when $K_{\mathrm{f}} \mathrm{t} t\left(\theta_{\mathrm{f}}-\theta_{\mathrm{i}}\right)$ decreases, the term $2 \mathrm{R}_{\mathrm{f}}(\mathrm{t})$ increases and then the wetted bulb is horizontally elongated. This happens in clay soils and when emitters deliver high discharges. It is also clear that initially drier the soil the narrower the bulb volume $\mathrm{V}_{\mathrm{b}}(\mathrm{t})$.

At the farm scale, the total effectively moistened soil volume $\mathrm{V}_{\mathrm{T}}(\mathrm{t})\left[\mathrm{L}^{3}\right]$ is the sum of the $\mathrm{N}$ bulbs being wetted by the $\mathrm{N}$ simultaneously operating emitters (Figure 1), so:

$$
V_{T}(t)=\sum_{i=1}^{N} V_{b i}(t)
$$

The fraction $(\mathrm{P})$ of the wetted soil volume is:

$$
\mathrm{P}=\frac{\mathrm{VT}(\mathrm{t})}{S_{T} \cdot Z_{f}(\mathrm{t})}=\frac{\sum_{i=1}^{N} \operatorname{Vbi}(\mathrm{t})}{S_{T} \cdot Z_{f}(\mathrm{t})}
$$

where $\mathrm{S}_{\mathrm{T}}\left[\mathrm{L}^{2}\right]$ refers to the total area equipped with $\mathrm{N}$ identical emitters discharging the same flow rate $\mathrm{q}$ in a uniform and homogeneous soil. Under these circumstances, the individual moistened bulbs are virtually similar. Thus, the combination of equations (3) and (4) provides:

$$
\mathrm{P}=\frac{\mathrm{N} \cdot \mathrm{Vb}(\mathrm{t})}{S_{T} \cdot Z_{f}(\mathrm{t})}
$$

The combination of equations (2) and (5) yields:

$$
P=\frac{2 \mathrm{~N} \pi}{3 S_{T} \cdot Z_{f}(\mathrm{t})} R_{f}^{2}(t)\left(2 R_{f}(\mathrm{t})+\frac{K_{f} \cdot \mathrm{t}}{\left(\theta_{f}-\theta_{i}\right)}\right)
$$



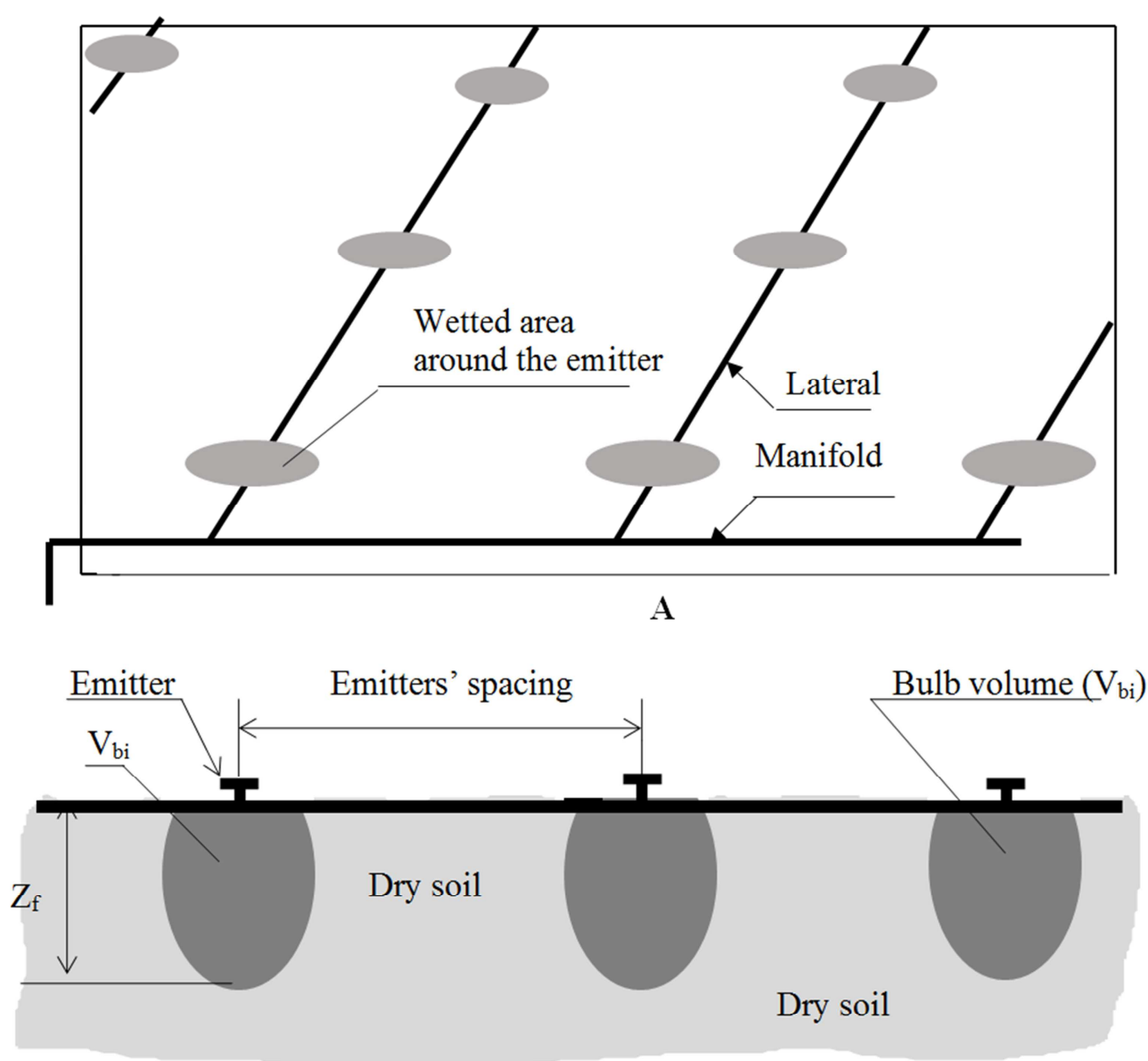

B

Figure 1. Scheme of the effectively wetted soil volume underneath trickle irrigation system.

\section{Optimizing Emitters' Density and Water Supplies}

\subsection{Required Emitters' Density}

The optimization of trickle irrigation systems is of prima facie importance. It provides appropriate diameters of laterals and manifolds that maximize emission uniformity (EU) and minimize the investment and management costs [22-24]. The overwhelming majority of the design approaches overlooks the effect of the emitters' density. Obviously, this is an acute assumption inasmuch as EU and the investment cost are closely dependent on the number of drippers at the farm scale as well as their manufacturing coefficient of variation [22, 25, 26]. Keller and Bliesner [27] reported that the unit cost of the system increases with the number of emitters per plant.

The emitters' density should guarantee a double objective: moisten a suitable rooted soil volume for crop productivity requirement and limit the pressure head loss to ascertain an acceptable uniformity emission and economy saving [28-30]. Subsequently, the determination of the soil fraction $\left(\mathrm{P}_{\mathrm{p}}\right)$ that fits crop water requirements at the peak period is of paramount importance. The peak period corresponds to the maximum rooted soil depth $Z_{\mathrm{m}}$, the maximum shaded strip width $2 \mathrm{R}_{\mathrm{m}}$ and the maximum evapotranspiration. Substituting $R_{m}$ and $Z_{m}$ for $R_{f}(t)$ and $Z_{f}(t)$ respectively, and equating $\left(P_{p}\right)$ and $(P)$ in equation (6) yields the required number $\mathrm{N}$ of emitters:

$$
N=\frac{3 P_{p} \cdot S_{T} \cdot Z_{m}}{2 \pi R_{m}^{2}\left(2 R_{m}+\frac{K_{f} \cdot \mathrm{t}}{\left(\theta_{f}-\theta_{i}\right)}\right)}
$$

Since the approach is valid for the infiltration phase, the number of emitters allows the replenishment of the rooted soil volume up to the maximum water content $\theta_{\mathrm{f}}$. Obviously, the risk of deep percolation is factual particularly at the end of the infiltration process. To prevent water loss, the soil moisture at the wetting front $\theta_{\mathrm{f}}$ is assumed to be equal to the soil moisture content at the field capacity $\theta_{c}$. Under these circumstances, the required number of emitters becomes:

$$
N=\frac{3 P_{p} \cdot S_{T} \cdot Z_{m}}{2 \pi R_{m}^{2}\left(2 R_{m}+\frac{K_{f} \cdot \mathrm{t}}{\left(\theta_{c}-\theta_{i}\right)}\right)}
$$

Equation (8) clearly shows that the higher emitter density $\mathrm{N}$ the larger the wetted soil fraction $\mathrm{P}_{\mathrm{p}}$. Moreover, for the same crop and the same field area $\left(\mathrm{Z}_{\mathrm{m}}, \mathrm{S}_{\mathrm{T}}\right.$, and $\left.\mathrm{P}_{\mathrm{p}}\right)$, higher $\mathrm{N}$ is needed in coarser textured soils. Conversely in fine textured soils, capillary forces are predominant and 
subsequently $\mathrm{R}_{\mathrm{f}}(\mathrm{t})$ is high. In this case, the emitters' spacing is larger. Finally, according to equation (8), the cost of the irrigation systems is strongly dependent on the soil type, the emitter discharge and the wetted soil fraction $\mathrm{P}_{\mathrm{p}}$. This latter depends on the crop, planting density and growing stage.

\subsection{Required Water Volume}

In essence, trickle irrigation involved supplying water to crops frequently but at low amounts so that the crop yield is maximum and water deep percolation and nutrients' leaching are minimum $[31,32]$. It is generally designed to wet only the rooted layer $[2,33]$. Thus, the soil holding capacity does not matter enough inasmuch as the main objective is just to maintain the rooted soil profile within prescribed moisture thresholds for optimal plant growth.

Henceforth, we assume that the irrigation network is in place and emitters' density and flow rates are fixed. Therefore, it is very important to determine the amount of water to be supplied $\left(\mathrm{Q}_{\mathrm{s}}\right)$ that ascertains the humidification of a soil fraction equal to the rooted one $\left(\mathrm{P}_{\mathrm{r}}\right)$. In trickle irrigated plot, the supplied water amount is:

$$
Q_{s}=N q t_{s}
$$

where $t_{s}[\mathrm{~T}]$ and $\mathrm{q}\left[\mathrm{L}^{3} \mathrm{~T}^{-1}\right]$ are the irrigation time and the average emitters' discharge, respectively. Regardless of leaching needs and deep percolation, the water volume required $\left(Q_{r}\right)$ to replenish the rooted soil fraction $P_{r}$, from an initial $\theta_{\mathrm{i}}$ up to $\theta_{\mathrm{c}}$, is:

$$
Q_{r}=P_{r} S_{T} Z_{r}\left(\theta_{c}-\theta_{i}\right)
$$

The mass conservation statement yields:

$$
t_{s}=\frac{P_{r} \cdot S_{T} \cdot Z_{r}\left(\theta_{c}-\theta_{i}\right)}{\mathrm{N} \cdot \mathrm{q}}
$$

Substituting $\mathrm{P}_{\mathrm{r}}$ for $\mathrm{P}$ (in equation 6), yields:

$$
t_{s}=\frac{2 \pi}{3 \mathrm{q}}\left(\Theta_{c}-\theta_{i}\right) R_{f}^{2}(t)\left(2 R_{f}(\mathrm{t})+\frac{K_{f} \cdot \mathrm{t}}{\left(\theta_{c}-\theta_{i}\right)}\right)
$$

Equations 11 and 12 clearly demonstrate that irrigation time $t_{s}$ is proportional to the rooted soil fraction $\left(\mathrm{P}_{\mathrm{r}}\right)$. Furthermore, it is also clear that the initially drier the soil the longer the irrigation time. Besides, the required irrigation time $\left(t_{s}\right)$ in fine textured soil is larger than that in coarse one because of the $\left(\theta_{c}-\theta_{i}\right)$ magnitude.

\section{Study Cases}

To illustrate the previous approach, Hammami's data [34] were used:

1) Silt soil: clay $=13 \%$, silt $=68 \%$, sand $=18 \%, \theta_{\mathrm{f}}=0.36$ $\mathrm{cm}^{3} \mathrm{~cm}^{-3}, \theta_{\mathrm{i}}=0.23 \mathrm{~cm}^{3} \mathrm{~cm}^{-3}, \mathrm{~K}_{\mathrm{f}}=0.35 \mathrm{~cm} / \mathrm{h}$ and soil bulk density $=1.28$. The curve $R_{f}(t)$ is drawn in figure 2.

2) Sandy soil: clay $=12 \%$, silt $=14 \%$, sand $=71 \%, \theta_{\mathrm{f}}=$ $0.23 \mathrm{~cm}^{3} \mathrm{~cm}^{-3}, \theta_{\mathrm{i}}=0.12 \mathrm{~cm}^{3} \mathrm{~cm}^{-3}, \mathrm{~K}_{\mathrm{f}}=1.17 \mathrm{~cm} / \mathrm{h}$ and soil bulk density $=1.46$. The curve $\mathrm{R}_{\mathrm{f}}(\mathrm{t})$ is depicted in Figure 2.

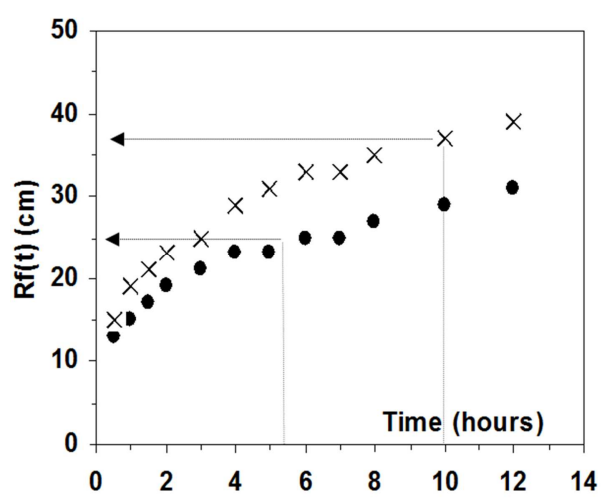

Figure 2. $R_{f}$ versus elapsed time in the infiltration phase $(q=2 \mathrm{l} / \mathrm{h})$ in silt

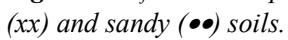

In these circumstances, what would be the number of emitters if the discharge is $2 \mathrm{l} / \mathrm{h}$, the moistened soil fraction $30 \%$ and the vertical rooted depth $50 \mathrm{~cm}$ at the peak period?

According to the aforementioned data, equation (1), yeilds:

$$
\begin{aligned}
& \text { Silty soil }: Z_{f}(t)=R_{f}(t)+1.35 t \\
& \text { Sandy soil }: Z_{f}(t)=R_{f}(t)+5.32 t
\end{aligned}
$$

where $Z_{f}(t)$ and $R_{f}(t)$ are expressed in centimeter and $t$ in hour, respectively.

Setting $Z_{\mathrm{f}}$ equal to $50 \mathrm{~cm}$ in equations (13) and (14) and using $\mathrm{R}_{\mathrm{f}}(\mathrm{t})$ curves depicted in Figure 2, the trial and error approach provides $\mathrm{R}_{\mathrm{f}} \approx 37.0 \mathrm{~cm}$ and $\mathrm{t} \approx 10.0 \mathrm{~h}$ for the silty soil and $\mathrm{R}_{\mathrm{f}} \approx 25.0 \mathrm{~cm}$ and $\mathrm{t} \approx 4.7 \mathrm{~h}$ for the sandy soil. Subsequently, equations (2) and (8) yield:

Silty soil: $\mathrm{V}_{\mathrm{b}}=0.143 \mathrm{~m}^{3}$ and $\mathrm{N} \approx 10360$ emitters per hectare,

Sandy soil: $\mathrm{V}_{\mathrm{b}}=0.065 \mathrm{~m}^{3}$ and $\mathrm{N} \approx 23080$ emitters per hectare.

It is worth to highlight that these emitters' densities are slightly overestimated. The discrepancy between optimized and expected values is attributable to the low initial water contents considered in the study cases. Indeed, a large difference between initial and final soil water contents is antagonistic with the principle of small and frequent water supply that characterizes trickle irrigation. On another side, equation (2) indicates that the smaller the difference $\left(\theta_{\mathrm{f}}-\theta_{\mathrm{i}}\right)$ the larger the bulb volume. The advance of the wetting front on the soil surface is enhanced by higher initial water contents.

In this backdrop, the irrigation management deals with the determination of the irrigation time for replenishing the fraction of the rooted soil volume $\left(\mathrm{P}_{\mathrm{r}}=30 \%\right.$ and $\left.\mathrm{Z}_{\mathrm{r}}=50 \mathrm{~cm}\right)$ from an initial water content $\theta_{\mathrm{i}}=0.12 \mathrm{~cm}^{3} \mathrm{~cm}^{-3}$ up to $\theta_{\mathrm{c}}=$ $0.23 \mathrm{~cm}^{3} \mathrm{~cm}^{-3}$ in sandy soil. For the silty soil, it is a matter of rising the water content from $\theta_{\mathrm{i}}=0.23 \mathrm{~cm}^{3} \mathrm{~cm}^{-3}$ up to $\theta_{\mathrm{c}}=$ $0.36 \mathrm{~cm}^{3} \mathrm{~cm}^{-3}$ to replenish the same fraction of the rooted soil volume. Substituting these values for $P_{r}, Z_{r}, \theta_{c}$ and $\theta_{i}$ in equation (11) provides $t_{s}=4.7 \mathrm{~h}$ for sandy soil and $t_{s}=10.0 \mathrm{~h}$ for silty soil. Using different irrigation times $\left(t_{\mathrm{s}}=5,2.5\right.$, and $1.25 \mathrm{~h}$ ) to apply the same gross water depth in a cropped sandy soil, Jamil et al. [35] reported that the highest fraction 
of the wetted area was recorded with $t_{s}=5 \mathrm{~h}$. This value is of the same order of magnitude than that calculated above $\left(\mathrm{t}_{\mathrm{s}}=\right.$ $4.7 \mathrm{~h}$ ) for the sandy soil.

\section{Discussion}

Using the aforementioned procedure, we derived the required values of $\mathrm{N}$ and $\mathrm{t}_{\mathrm{s}}$ for different drip irrigation scenarios with sandy and silty soils (table.1). It is worth pointing out that the emitters' density strongly depends on the soil texture and the fraction $\mathrm{P}$ being wetted. In turn, irrigation time $t_{s}$ is tightly dependent on emitter's discharge, rooted soil depth $Z_{r}$ and water deficit $\left(\theta_{c}-\theta_{i}\right)$.

In sum, the implementation of Hammami and Zayani [3] approach for optimizing emitters' density and trickle irrigation management requires the following inputs:

1) soil water retention curve,

2) $\theta_{c}$ and $\theta_{i}$ values which must be fixed according to the crop growth and water requirements,

3) hydraulic conductivity at the wetting front position
$\mathrm{K}\left(\mathrm{h}_{\mathrm{f}}\right)$. This value could be inferred from the capillary model of Mualem [36]. It shoud be highlighted that this approach accuracy is strongly dependent on the wise choice of the pressure head $\left(\mathrm{h}_{\mathrm{f}}\right)$ prevailing at the wetting front. Many authors claim that $h_{f}$ value ranges between $-20 \mathrm{mb}$ and $-40 \mathrm{mb}$ in coarse textured soils and between $-40 \mathrm{mb}$ and $-60 \mathrm{mb}$ in fine textured ones [37, 38],

4) wetting front radius or the lateral rooting spread $R_{f}$. This parameter could be easily fitted to the half width of the shaded strip at the soil surface [39],

5) crop characteristics that encompass plantation density, daily crop water requirements, and the fraction of the rooted soil volume $\mathrm{P}_{\mathrm{r}}$. Even though objective criteria for estimating this parameter are lacking, it is often hypothesized that $\mathrm{P}_{\mathrm{r}}$ lies between $33 \%$ and $67 \%$ [1]. Keller and Bliesner [27] reported a percentage ranging between $50 \%$ up to $60 \%$ for arid area and $40 \%$ in rainy area.

Table 1. Emitters' density and irrigation time for different irrigation management scenarios proposed for the silty and the sandy soils.

\begin{tabular}{|c|c|c|c|}
\hline \multicolumn{2}{|l|}{ Sandy soil } & \multicolumn{2}{|l|}{ Silty soil } \\
\hline $\operatorname{Pr}=30 \%)$ & & $\operatorname{Pr}=30 \%)$ & \\
\hline $\left.\begin{array}{rl}\mathrm{Zr} & =50 \mathrm{~cm} \\
\mathrm{q} & =2 \mathrm{l} / \mathrm{h}\end{array}\right\}$ & $\mathrm{N} \approx 23080$ and $\mathrm{ts}=4.7 \mathrm{~h}$ & $\left.\begin{array}{rl}\mathrm{Zr} & =50 \mathrm{~cm} \\
\mathrm{q} & =2 \mathrm{l} / \mathrm{h}\end{array}\right\}$ & $\mathrm{N} \approx 10360$ and ts $=10.0 \mathrm{~h}$ \\
\hline $\left.\begin{array}{rl}\mathrm{Zr} & =50 \mathrm{~cm} \\
\mathrm{q} & =2 \mathrm{l} / \mathrm{h}\end{array}\right\}$ & $\mathrm{N} \approx 24560$ and $\mathrm{ts}=4.7 \mathrm{~h}$ & $\left.\begin{array}{rl}\mathrm{Zr} & =50 \mathrm{~cm} \\
\mathrm{q} & =2 \mathrm{l} / \mathrm{h}\end{array}\right\}$ & $\mathrm{N} \approx 10740$ and ts $=10.0 \mathrm{~h}$ \\
\hline $\left.\begin{array}{rl}\mathrm{Zr} & =50 \mathrm{~cm} \\
\mathrm{q} & =4 \mathrm{l} / \mathrm{h}\end{array}\right\}$ & $\mathrm{N} \approx 18270$ and $\mathrm{ts}=4.2 \mathrm{~h}$ & $\left.\begin{array}{rl}\mathrm{Zr} & =50 \mathrm{~cm} \\
\mathrm{q} & =4 \mathrm{l} / \mathrm{h}\end{array}\right\}$ & $\mathrm{N} \approx 8520$ and ts $=7.0 \mathrm{~h}$ \\
\hline $\left.\begin{array}{rl}\mathrm{Zr} & =50 \mathrm{~cm} \\
\mathrm{q} & =4 \mathrm{l} / \mathrm{h}\end{array}\right\}$ & $\mathrm{N} \approx 24120$ and $\mathrm{ts}=4.2 \mathrm{~h}$ & $\left.\begin{array}{rl}\mathrm{Zr} & =50 \mathrm{~cm} \\
\mathrm{q} & =4 \mathrm{l} / \mathrm{h}\end{array}\right\}$ & $\mathrm{N} \approx 10510$ and $\mathrm{ts}=7.0 \mathrm{~h}$ \\
\hline $\left.\begin{array}{rl}\mathrm{Zr} & =70 \mathrm{~cm} \\
\mathrm{q} & =4 \mathrm{l} / \mathrm{h}\end{array}\right\}$ & $\mathrm{N} \approx 27100$ and $\mathrm{ts}=7.0 \mathrm{~h}$ & $\left.\begin{array}{rl}\mathrm{Zr} & =70 \mathrm{~cm} \\
\mathrm{q} & =4 \mathrm{l} / \mathrm{h}\end{array}\right\}$ & $\mathrm{N} \approx 11010$ and $\mathrm{ts}=14.0 \mathrm{~h}$ \\
\hline
\end{tabular}

\section{Conclusion}

Trickle irrigation is designed and managed so that the wetted bulb underneath the emitters fits the rooted volume. A new approach for computing the effectively wetted soil volume under trickle irrigation systems was proposed by Hammami and Zayani [3]. The approach offers guidelines for network design and irrigation management. For trickle networks' design, the approach enables the adjustment of the emitters' density with the wetted bulb volume so that crop water requirements are fulfilled even in the peak season. For management purpose, the approach enables the inference of the irrigation time that ascertains the replenishment of the rooted soil volume up to a prescribed threshold.

The present approach has the advantage of fulfilling the conservative aspect of the network design and the dynamic aspect of irrigation management. Indeed, for design purposes, the irrigation time could be set equal to the required duration that generates a quasi-steady state flow or to that needed during the peak period. By cons, irrigation scheduling should be flexible so that design errors are mitigated. This flexibility could be achieved by adjusting the irrigation time to the fraction of the wetted soil volume required at the actual cropping season (equation 11).

\section{References}

[1] Sawa Andreas P. and Frenken Karen, 2002. Localized irrigation systems Planning, Design Operation and Maintenance. Irrigation Manual, Module 9. Frontline Electronic Publishing, Harare, Zimbabwe. Printed by: Préciex, Les Pailles, Mauritius.

[2] Jianhua Zheng, Guanhua Huang, Dong dong Jia, Jun Wang, Mariana Mota, Luis S. Periera, Quanzhong Huang, Xu Xu, Haijun Liu, 2013. Reponses of drip irrigated tomato (Solanum Lycopersicum) yield, quality and water productivity to various soil matric potential thresholds in an arid region of Northwest China. AGWAT 129: 181-193.

[3] Hammami Moncef and Zayani Khemaies, 2016. An analytical approach to predict the moistened bulb volume beneath a surface point source. AGWAT. 166: 123-129.

[4] Al-Ogaidi A. M., Wayayok, A., M. K. R., Abdullah, A., 2015. A Modified Empirical Model for Estimating the Wetted Zone Dimensions under Drip Irrigation. Journal Teknologi. 76, 69-73. 
[5] Healy W. and Warrick A. W., 1988. A generalised solution to infiltration from surface soil point source. Soil Sci. Soc. Am. J., 52: 1245-1251.

[6] Schwartzman, B. M. and Zur, B., 1986. Emitter Spacing and Geometry of Wetted Soil Volume. J. Irrig. Drain. Eng. (ASCE) $112,242-253$.

[7] Keller J. and Karmelli D., 1974. Trickle irrigation design parameters. Trans. ASEA.

[8] Ahmed A. M. Al-Ogaidi, Aimrun Wayayok, M. K. Rowshon, Ahmed Fikri Abdullah 2016. Wetting patterns estimation under drip irrigation systems using an enhanced empirical model. Agric. Water Manag. Vol. 176 (203-213).

[9] Ababou R., 1981. Modélisation des transferts hydriques dans le sol en irrigation. Thèse Docteur-Ingénieur, Institut Polytechnique de Grenoble.

[10] Lafolie F., Guennelon R., Van Genuchten M. Th., 1989a. Analysis of water flow under trickle irrigation: I. Theory and numerical solution. Soil Sci. Soc. Am. J. 53: 1310-1318.

[11] Cook, F. J., Thorburn, P. J., Fitch, P., Bristow, K. L., 2003. WetUp: a software tool to display approximate wetting pattern from drippers. Irrig. Sci. 22, 129-134.

[12] Communar Gregory, Friedman Shmulik P., 2013. Unsteady infiltration from pointand line sources in laterally confined domains. Soil Sci. Soc. Am. J. 77, 1529.

[13] Brunetti G., Simunek J., Bautista E., 2018. A hybrid finite volume-finite element model for numerical analysis of furrow irrigation and fertigation. Journal of Computers an Electronics in Agriculture 150. DOI: 10.1016/j. compag. 2018.05.01.

[14] Revol P., Brent E., Kosuth P. and Vachaud G., 1996. The freewater pond under a trickle source: a field-test of existing theories Irrig. Sci., 16: 169-173.

[15] Wooding R. A., 1968. Steady infiltration from a shallow circular pond. Water Resour. Res., 4: 12598-1273.

[16] Raats P. A. C., 1971. Steady infiltration from point sources cavities and basins. Soil Sci. Soc. Am. J., 35: 689-694.

[17] Philip J. R., 1985. Steady absorption from spheroidal cavities. Soil Sci. Soc. Am. J., 49: 828-830.

[18] Sen H. S, D. Paul, K. Bandyopadhyay, and N. B. Dash, 1992. A simple numerical solution for two-dimensional moisture distribution under trickle irrigation. Soil Sci. 154: 350 - 356.

[19] Coelho E. F. and D. Or, 1997. Applicability of analytical solutions for flow from point sources to drip irrigation management. Soil Sci. Soc. Am. J., 61 : 1331-1341.

[20] Warrick A. W., 1974. Time-dependent linearized infiltration. I. Point sources. Soil Sci. Soc. Am. J., 38: (384-386).

[21] Hammami M., Daghari H., Balti J. and Maalej M., 2002. Approach for predicting the wetting front depth beneath a surface point source: Theory and numerical aspect. Irrig. and Drain. 51: 347-360.

[22] Carrion F., Turjuelo J. M., Hernandez D., and Moreno M. A., 2013. Design of micro irrigation subunit of minimum costs with proper operation. Irrig. Sci. Springer. Vol. 31 (5): 11991211.

[23] Zayani K. and Hammami M., 2009. Design of level ground laterals in trickle irrigation systems. Journal of Irrigation and Drainage Engineering (ASCE), Vol. 135, n5: 620-625.

[24] Zayani K., Hammami M., Alouini A. and Souissi A., 2013. Design of Nonzero Uniformly sloping Laterals in Trickle Irrigation Systems. Journal of Irrigation and Drainage Engineering (ASCE): Vol. 139 (5): 419-425.

[25] Alaa Nabil El-Hazek, 2016. Revision approach of optimum design of pressurized irrigation system. Archives of Current Research International 5 (3): 1-10.

[26] Asif, M. M. Ahmad, A. G. Mangrio, G. Akbar, A. H. Memon. 2015. Design, Evaluation and Irrigation Scheduling of Drip Irrigation System on Citrus Orchard. Pakistan Journal of Meteorology, Vol. 12, Issue 23.

[27] Keller, J. and Bliesner R. D., 1990. Sprinkler and Trickle Irrigation. Van Nostrand Reinhold, New York..

[28] Palau-Salvador G., Sanchis L., Gonzalez-Altozano P., ArvizaValverde J., 2006. Real local losses estimation for on-line emitters using empirical and numerical procedure. J. Irrig. Drain. Eng. 132 (6): 522-530.

[29] Provenzano G. and Pumo D., 2004. Experimental analysis of local pressure losses for micro-irrigation laterals. J. Irrig. Drain. Eng. 130 (4): 318-324.

[30] Sayed-Hossein Sadeghi, Troy Peters, and Vakhtang Shelia, 2016. Energy Grade line assessment for tapered micro irrigation laterals. . J. Irrig. Drain. Eng. 04016054 (ASCE).

[31] Konstantinos X. Soulis, and Stamatios Elmaloglou, 2016. Optimum Soil Water Content Sensors Placement in Drip Irrigation Scheduling Systems: Concept of Time Stable Representative Positions. J. Irrig. Drain. Eng. 04016054 (ASCE).

[32] Sammis T., Charma P., Shuka M. K., Wang J., Miller D., 2012. A water-balance drip-irrigation scheduling model. AGWAT 113: 30-37.

[33] Al-Qinna, M. L, Abu-Awwad A. M., 2001. SW-Soil and Water: Wetting Patterns under Trickle Source in Arid Soils with Surface Crust. Journal of Agriculture engineering research, 80: 301-305.

[34] Hammami Moncef., 2001. Nouvelle Approche pour déterminer le volume de sol humidifié par un goutteur. Thèse de Doctorat d'état es-sciences physiques. Faculté des sciences mathématiques, physiques et naturelles de Tunis.

[35] Jamil Ahmed, Issam Daghari, and Ali Gharbi, 2016. Analysis of Several Discharges - Durations - Drip Line Placements under Mango Trees. International Journal of Advanced Research, Vol. 4 (7): 968-984.

[36] Mualem, Y., 1976. A new model for predicting the hydraulic conductivity of unsaturated porous media. Water Resour. Res. $12,513-522$.

[37] By Fred L. O. and Bahram S., 1997. Green and Ampt infiltration with redistribution. Journal of irrigation and drainage engineering, 123: 386-393.

[38] Hillel D., 1988. L'eau et le sol: principes et processus physiques. Traduit de l'anglais par Lui W. De Backer. Louvain-la-neuve Académia.

[39] Lubana P. P. S. and Narda N. K., 1998. Soil water dynamics model for trickle irrigated tomatoes. Agricultural water management, 37: $145-161$. 